\title{
Techno-economic analysis of waste heat recovery by inverted Brayton cycle applied to an LNG-fuelled transport truck
}

\author{
Kirill Abrosimov ${ }^{1 *}$, Federica Sciacchitano ${ }^{2}$, Gianluca Pasini ${ }^{2}$, Andrea Baccioli ${ }^{2}$, Aldo Bischi ${ }^{1}$ and Marco \\ Antonelli ${ }^{2}$ \\ ${ }^{1}$ Skolkovo Institute of Science and Technology, Moscow, Russian Federation \\ ${ }^{2}$ Department of Energy, Systems, Territory and Constructions Engineering (DESTeC), University of Pisa, Italy
}

\begin{abstract}
Aiming for the better environmental and economic performance of traditional engines, waste heat recovery (WHR) technologies are actively studied to find their most beneficial applications. In this work, the inverted Brayton cycle (IBC) is investigated as a potential WHR solution for liquefied natural gas (LNG) fuelled transport truck. LNG being one of the less polluting fossil fuels is widely spreading nowadays in different industries due to the rapid development of the LNG supply chain in the world. LNG-fuelled cargo transportation follows this prevailing trend. Based on the overexpansion of flue gases to subatmospheric pressure, inverted Brayton cycle, in turn, is considered a prospective technology of WHR and techno-economic analysis of IBC in several configurations on-board of a heavy transport truck have been assessed. IBC is integrated into the engine cooling system in the basic layout, and additionally, it incorporates LNG regasification process in advanced configurations. Power balance based on Aspen Hysys model enables to perform system optimisation and gives preliminary design parameters of the system components. Cost function approach provides the basis for a preliminary economic assessment of the layouts. Although the system shows fuel economy of maximum about $2.1 \%$, analysis revealed the necessity to continue the search for better technical solutions in IBC-based systems to make them economically attractive due to high cost of installed equipment.
\end{abstract}

\section{Introduction}

The transport sector is one of the central topics in European debates for the reduction of greenhouse gases and polluting emissions of NOx, CO, and soot. In particular, heavy vehicles, including trucks, buses, and coaches, are in charge for around $6 \%$ of the total carbon dioxide $\left(\mathrm{CO}_{2}\right)$ emissions and about $25 \%$ of the total $\mathrm{CO}_{2}$ emissions generated by road transport in the European Union [1]. With the new regulation (EU) 2019/1242, the target levels of $\mathrm{CO}_{2}$ performance of modern heavy vehicles have been normalised by the values of vehicle fleet average emissions monitored in the 2019-2020 period. In particular, a reduction is expected: by $15 \%$ starting from 2025 and by $30 \%$ starting from the year 2030 referencing 2019-2020 level. As regards to polluting emissions, Euro VI standards have been in force since 2014. This regulatory framework relating to the transport sector has increased the interest in improving the energy efficiency of internal combustion engines with $a$ consequent reduction in fuel consumption and the search for cleaner fuels with a lower content of carbon, like liquefied natural gas (LNG). LNG is made up of $90-99 \%$ of methane and the remaining part consisting of other gases such as propane, ethane, nitrogen, and carbon dioxide.
Liquefaction involves a reduction of the specific volume of about 600 times, with advantages in terms of vehicle range in comparison with other solutions such as compressed natural gas $(\mathrm{CNG})$. Among the advantages over traditional diesel (EURO VI) LNG has lower $\mathrm{CO}_{2}$, carbon monoxide, NOx and particulate matter emissions [2].

In order to improve the energy efficiency of internal combustion engines, systems for recovering residual energy from the exhaust gases, which represents around $30 \%$ of the energy input to the engine, have been studied with increasing interest. Among the various existing systems such as turbo-compound systems (TS), Organic Rankine Cycle (ORC) and Thermo-Electric Generator (TEG), the inverted Brayton cycle (IBC) could represent an interesting alternative (Bianchi \& De Pascale, 2011 [3]). In comparison with other mechanical waste heat recovery (WHR) systems like ORC, IBC contributes to the simplicity and compactness of the components, which are especially important where weight and dimensions constitute a binding problem for the installation of WHR systems. Comparison with nonmechanical technologies like TEG shows better economic performance of the studied approach.

In this discussion, the waste heat recovery system based on the IBC applied to the exhaust gas of internal

\footnotetext{
*Corresponding author: kirill.abrosimov@ skolkovotech.ru
} 
combustion engine was analysed with the aim of assessing the technical-economic feasibility for a real case of an LNG-fuelled heavy transport vehicle.

\section{Methodology}

The model was built in commercial software Aspen Hysys. Effect of the WHR system operation is evaluated as the reduced fuel consumption of the main engine due to additional power generated by IBC. On the other side, the negative effect of the system associated with additional mass on-board is evaluated with experimental interpolations from literature. Available technical reports ([4], [5], [6]) on the case-study truck gave the basic fuel consumption and performance data in different driving modes. Economic analysis is based on the simple non-discounted cash flow approach with the cost of the WHR system based on the cost-functions of the main components. The following section gives further details on this methodology.

\subsection{Case study}

As a case-study, the Iveco Stralis NP-400 has been chosen as an example of a modern heavy transport truck fuelled with LNG. Based on data from [4], Table 1 shows its main characteristics. In this work, LNG is considered being pure methane for sake of simplicity

Table 1. Iveco Stralis NP-400 characteristics

\begin{tabular}{cc}
\multicolumn{2}{c}{ General information } \\
\hline Vehicle type & $\mathrm{N} 3$ \\
LNG tank capacity & $2 \times 5981$ \\
LNG storage pressure & $8.2 \mathrm{bar}$ \\
Tractor weight & $7760 \mathrm{~kg}$ \\
Trailer weight & $7400 \mathrm{~kg}$ \\
Max transportable weight & $28840 \mathrm{~kg}$ \\
\hline \multicolumn{2}{c}{ Engine characteristics } \\
\hline Model & Cursor 9 \\
Combustion type & Stoichiometric \\
Displacement & 8.711 \\
Euro class & Euro VI \\
Supercharging & Present
\end{tabular}

According to FIGE ETC (Forschungsinstitut für Geräusche und Erschütterungen European Transient Cycle) [5], there are three main modes, or phases, of the truck operation: Urban, Rural and Motorway. In the techno-economic assessment of this paper, the WHR system is conservatively assumed to operate only in Motorway and Rural regimes, as it provides a relatively constant high engine load with a high temperature of the exhaust. For urban streets, the WHR system is considered to be by-passed. Besides, $90 \%$ operation time in the Rural phase to consider possible severe nondesign operation conditions of turbomachines when IBC has to be by-passed

Table 2. Standard test regime of heavy truck (UE) N.582/2011 [7]

\begin{tabular}{ccc} 
Phase of operation & Velocity, $\mathbf{~ k m} / \mathbf{h}$ & Duration, \% \\
\hline Urban & $0-50$ & $20 \pm 5$ \\
Rural & $50-75$ & $25 \pm 5$ \\
Motorway & $>75$ & $55 \pm 5$
\end{tabular}

The time distribution between operation modes and range of velocity for each mode for N3 type vehicle are presented in Table 2 [7].

Iveco truck engine performance tested in accordance with (UE) N.582/2011 regulation is reported in [4]. In particular, the engine performance map may be seen in Figure 2. $1500 \mathrm{rpm}, 650 \mathrm{Nm}$ point is chosen as an average operation point of the most frequent engine rotation speed for the motorway phase, and $1300 \mathrm{rpm}$, $650 \mathrm{Nm}$ as an average point of the second most frequent engine rotation speed for the rural phase. These points are used for the calculations. In the Urban phase, WHR unit is by-passed, and parameters of the engine operation are not specified.

Another important parameter for this study is the temperature of the exhaust gases. It was assessed based on the Zhang et al. (2016) [8]. The reference temperature value for the considered operation points marked with circles in Figure 1 is equal to $550{ }^{\circ} \mathrm{C}$.

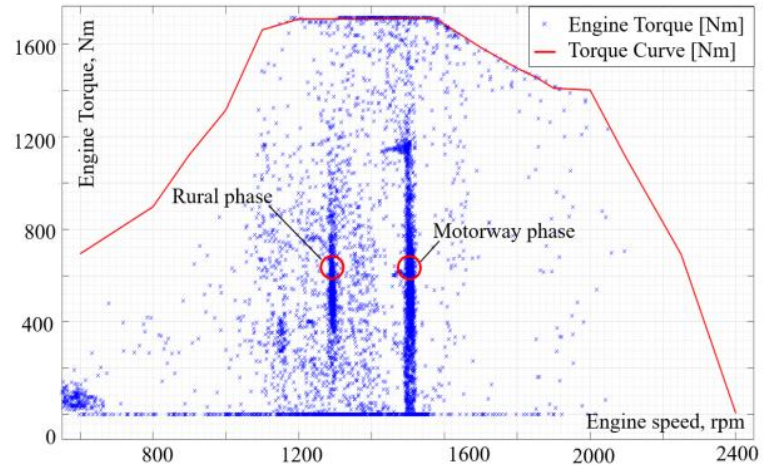

Fig. 1. Engine Torque - Engine Speed map [4]

\subsection{Methodology of fuel consumption calculation}

Fuel consumption in the different modes is assessed by application of linear interpolation of $\mathrm{CO}_{2}$ emission per kilometre from another experimental study of the similar heavy-duty truck fuelled with diesel instead of LNG [6] considering equal powertrain efficiency. Coefficients of the interpolation are presented in Table 3. Equation 1 shows the formula, which is used to calculate final values of $\mathrm{LNG}$ consumption per $\mathrm{km}$, considering the initial linear interpolation, and recalculation procedure of the diesel flow rate to LNG.

Table 3. Interpolation coefficients and average velocity for different phases of ETC [6]

\begin{tabular}{c|ccc} 
Drive cycle & $\begin{array}{c}\text { Urban } \\
\text { phase - 1 }\end{array}$ & $\begin{array}{c}\text { Rural } \\
\text { phase - 2 }\end{array}$ & $\begin{array}{c}\text { Motorway } \\
\text { phase - 3 }\end{array}$ \\
\cline { 2 - 4 } Gradient A & 0.0367 & 0.0216 & 0.0143 \\
Constant B & 273.6 & 329.4 & 488.6 \\
$\begin{array}{c}\text { Average } \\
\text { speed, km/h }\end{array}$ & 22.8 & 69 & 84
\end{tabular}

Where $M_{v e h}[\mathrm{~kg}]$ is the mass of the truck, $\rho_{\text {diesel }}=$ $835\left[\mathrm{~kg} / \mathrm{m}^{3}\right]$ stands for the density of diesel fuel, $\mathrm{CO}_{2 l}=2.65\left[\mathrm{~kg} / l_{\text {diesel }}\right]$ is the $\mathrm{CO}_{2}$ emission factor per one litter of diesel fuel, $\mathrm{LHV}_{\text {diesel }}=42.6[\mathrm{MJ} / \mathrm{kg}]$, $\mathrm{LHV}_{\mathrm{LNG}}=49[\mathrm{MJ} / \mathrm{kg}]$. Besides, obtained values of the 
fuel rate enable to assess the exhaust gas flow rate and composition, since the engine runs in stoichiometric condition [2] giving results corresponding to other sources, e.g. [8].

$$
\begin{aligned}
& C_{L N G_{-} k m}=\left(\left(B+A \cdot M_{\text {veh }}[\mathrm{kg}]\right)\left[\frac{\mathrm{g}}{\mathrm{km}}\right] \cdot \frac{1}{C_{2 l_{\_} \text {diesel }}\left[\frac{\mathrm{kg}}{\mathrm{l}}\right]}\right) . \\
& \rho_{\text {diesel }}\left[\frac{\mathrm{kg}}{\mathrm{m}^{3}}\right] \cdot \frac{L H V_{\text {diesel }}}{L H V_{L N G}},\left[\frac{\mathrm{kg}}{\mathrm{km}}\right] \quad \text { Eq. } 1
\end{aligned}
$$

For the calculation of the benefit coming from the IBC-WHR system, the power recovered is simply added to the ICE one to satisfy the entire load, assuming all the mechanical energy converted into electric, giving the consequent fuel saving. Saved fuel enables to compute the cash flow in $\$ / \mathrm{km}$. The price of the kilogram of LNG for Italy (price LNG $=0.96 € / \mathrm{kg}$ [9]) was converted to dollar of 2018 [10].

\subsection{Studied system}

Inverted Brayton cycle as a technical solution for WHR was suggested decades ago; Dunteman in 1970 [11] was one of the first who investigated it in detailes. But only recently this concept got a new wave of attention in the scientific literature. In particular, the application of IBC for the reciprocating engine bottoming is studied by Kennedy et al. [12] and Di Battista et al. [13] for light vehicles, or Di Battista et al. [14] for heavy vehicles whose models show good results from thermodynamic point of view. Kennedy et al. report about 5\% decrease in brake specific fuel consumption. Di Battista et al. demonstrated $3.5 \%$ of the brake mechanical power recovery [14], and $3.4 \%$ net efficiency increase in a later work [13] underlining the operability of the system only under the engine load above $70 \%$.

The principle of operation of the IBC is described in details in [12]. Briefly, the hot exhaust gas leaving its source (reciprocating engine in the studied case) comes to the turbine of IBC with near atmospheric pressure. It expands in the turbine down to the subatmospheric pressure, which is generated by the compressor standing downstream. Then the gas cools down in the cooler and get back to the atmosperic pressure with the compressor. Although this cycle enables to direct exhaust straight to the turbine without intermediate fluid, cooling before the compressor should be intense to cool the exhaust gas down to provide an essential difference between the turbine produced work and compressor consumed work.

In regards to the LNG supply system, two configurations are studied. One configuration uses only engine coolant as coolant for IBC; another one exploits also LNG regasification process as a cooling source for IBC as well. The second configuration is presented in Figure 2. The first configuration is similar but without HE2. Fuel pressure after regasification equals to LNG pressure under $-128{ }^{\circ} \mathrm{C}$ ( 8.2 bar) minus pressure losses.

There are several assumptions on this integration:

- No new air-cooled radiators are introduced to avoid increase in the truck air resistance or electric consumption.

- The maximum capacity of the original radiator is higher than the normal load capacity by at least $25 \%$ because it is sized for full engine power and atypically hot ambient conditions. It allows using the coolant of the main cooling circuit of the truck as a coolant for the IBC. For the cases of maximal engine load, IBC loop could be by-passed.

- Minimal coolant temperature for normal operation is $85^{\circ} \mathrm{C}[15]$.

- Maximal coolant temperature for normal operation is $95^{\circ} \mathrm{C}[15]$.

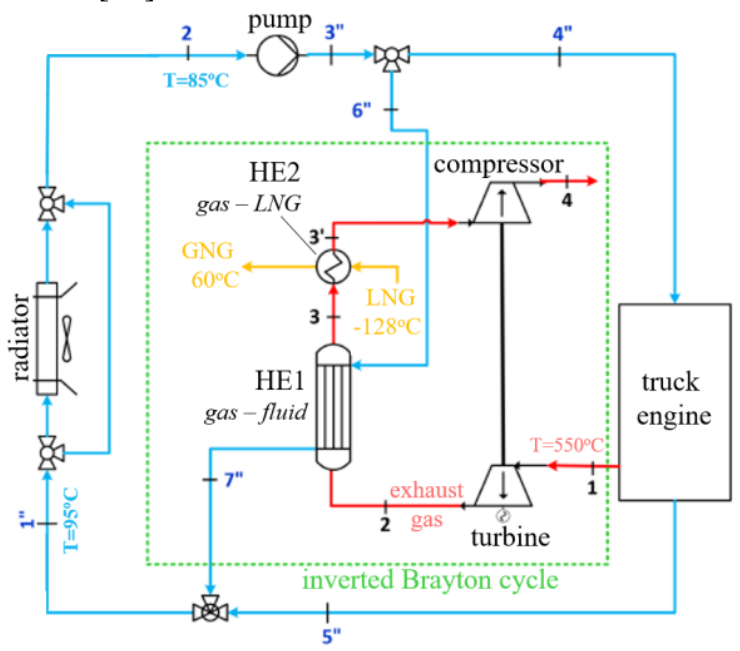

Fig. 2. Configuration 2 of the integrated system Engine + IBC

\subsection{System simulation in Aspen Hysys}

The system was simulated in the commercial software Aspen Hysys V9. Thermodynamic equations used for this simulation are presented, in Abrosimov et al. (2020) [16] .

The Aspen sensitivity-analysis tool was used for the optimisation of the scheme with different HE types as only the pressure after the turbine was a variable, assuming the IBC inlet pressure (as well as IBC outlet) equal to atmospheric (1.013 bar). It resulted in a certain value of turbine and compressor pressure ratios calculated as $P R_{T}=p_{T . \text { in }} / p_{\text {T.out }}$ and $P R_{C}=p_{\text {C.out }} /$ $p_{\text {C.in }}$.

Peng-Robinson is used as equation of state in Aspen.

\subsection{Weight and Cost Assessment}

Main components of the system are turbomachines and heat exchangers (HEs). Different approaches for weight and cost assessment were applied. The turbine and compressor are assumed to be taken from the catalogs of heavy truck turbo-compressor producers. The turbomachinery unit cost presented in Table 4 is based on the study of available spare-parts on the American internet market [17] with some additional cost associated with re-arrangement.

The gas cooling heat exchanger after the turbine (HE1) is an important part of the system, which determines both efficiency and cost of the system. For choosing the HE1 type, the following should be contemplated: 
- One side of HE1 is under vacuum conditions, so suitable casing should be applied

- The highest temperature is above $400{ }^{\circ} \mathrm{C}$, so some materials (e.g. aluminium) and HE types (e.g., plateand-frame due to sealing issues) cannot be used

- To provide reasonable system efficiency, considering a relatively high temperature of the coolant, effectiveness $\left(\sigma=T_{\text {hot.in }}-T_{\text {hot.out }} / T_{\text {hot.in }}-T_{\text {cold.in }}\right)$ of the HE1 should be the highest possible.

- To provide higher efficiency of the WHR unit, pressure losses in HEs should be the lowest possible. Relative pressure losses $\Delta \mathrm{p}=\left(p_{\text {in }}-p_{\text {out }}\right) / p_{\text {in }}$ are used for this assessment

These considerations bring out two types of the main heat exchangers, which are in the focus of this work: plate-fin type and shell-and-tube type.

Both heat exchangers are relatively small, so it is quite challenging to apply the usual cost-function assessment technique (e.g., based on [18]) for the considered type and size of HEs. Besides, this method is subjected to criticism in the literature (e.g. [19]) as the 25 years old data may not consider progress in manufacturing technologies. That is why a range of possible cost was assessed based on the several literature sources.

One of the cost estimations for the shell-and-tube HE is based on Hewitt \& Pugh (2007) [20] who give the interpolation for the cost of plate-and-frame HEs in the range of the working area $0.1-1000 \mathrm{~m}^{2}$, where HE1 fits in. Then, the obtained value is multiplied by three, following the comparison of the manufacturing cost of plate-and-frame and shell-and-tube HEs in Kananeh et al. (2012) [21]. Conversion from UA [W/K] available in Aspen to the effective heat-transfer area of the HE $\left(\mathrm{A}_{\text {eff }}\right.$ $\left.\left[\mathrm{m}^{2}\right]\right)$ is based on the assumption of $\mathrm{U}=75\left[\mathrm{~W} / \mathrm{m}^{2} \mathrm{~K}\right]$ for the effective overall heat conductance in case of heat exchange between low-pressure gas and brines [22]. For the assessment of the high cost bound of the plate-fin HE, ESDU (1995) [23] graphical cost-function was used relying on the active volume $\left(\mathrm{V}_{\text {act }}\right)$ of $\mathrm{HE}$. The $\mathrm{V}_{\text {act }}=$ $500 \cdot \mathrm{A}_{\text {eff }}$ ratio from [20] gives an approximate assessment of the this parameter for plate-fin HE based on the $A_{\text {eff }}$ available from Aspen Hysys model. In this study, $V_{\text {act }}$ is observed varying around $0.01 \mathrm{~m}^{3}$ for platefin, and around $0.05 \mathrm{~m}^{3}$ for shell-and-tube. Hewitt \& Pugh reference a source in British pounds of 1995, [23] is in British pounds of 1997 which are converted to US dollars 2018 using the currency exchange rate for 1995 and 1997 [10] and CEPCI cost index [24].

An alternative source of the cost estimation is Xie et al. (2008) [25] who estimate a larger size plate-fin HE with about 5 times lower cost than the approach described above has shown. Besides, studying of the Chinese internet market [26] has demonstrated that available costs of some components are much lower than it could be calculated with classical cost-function methods. Considering the fact that this paper is trying to assess the practical value of the technology, sources of the cost data such as [26] should be considered.
For HE2, which is a gas cooler at one side, and LNG regasifier at the other, different types of $\mathrm{HE}$ are in use, for example, Dorosz et al. (2018) [27] mention brazed plate and shell-and-tube HEs as possible types. However, as in many other literature sources, the phase change $\mathrm{HE}$ is described as quite a complex system, usually consisting of several sections and combining HEs of different types to compensate high superheating of the gas phase. The cost of HE2 is also given as a range based on the calculation of the shell-and-tube HE and plate-fin HE. The procedure is similar to HE1 with $\mathrm{V}_{\text {act }}$ in the range $0.0015-0.01 \mathrm{~m}^{3}$.

Here, the plate-fin type as is chosen as conservative solution being one of the most expensive types of HEs.

The assessment of HEs weight range is based on several HE configurations obtained in Aspen Hysys HE design add-in. Thus the mass of HEs was assessed as a range, which contains the plate-fin $\mathrm{HE}$ as a low bound and shell-and-tube as a high bound.

As the additional system increases the overall mass of the truck, it is important to consider this effect on fuel consumption. The chosen method of fuel consumption calculation allows doing that as the variable in Equation 1 is the mass of the vehicle $\left(M_{v e h}\right)$.

Cash flow discounting is not accounted for in the economic analysis of this work. Operation and maintenance (O\&M) expenditures are neglected as they do not affect much overall truck O\&M costs.

\section{Results}

Table 4. Parameters of IBC components

\begin{tabular}{|c|c|c|c|c|}
\hline Component & Type & $\begin{array}{c}\text { Additional } \\
\text { features }\end{array}$ & Cost, \$ & $\begin{array}{c}\text { Weight, } \\
\text { kg }\end{array}$ \\
\hline Turbine & Radial & $\eta_{\text {is }}=0.8$ & 100 & 10 \\
\hline Compressor & Radial & $\eta_{\text {is }}=0.8$ & & \\
\hline HE1 & $\begin{array}{l}\text { Plate-fin / } \\
\text { shell- } \\
\text { and-tube }\end{array}$ & $\begin{array}{c}\sigma=0.95 / 0.9 \\
\Delta \mathrm{p}=0.035 / 0.025 \\
\mathrm{~T}_{\text {oil.in }}=85^{\circ} \mathrm{C} \\
\mathrm{T}_{\text {oil.out }}=95^{\circ} \mathrm{C}\end{array}$ & $\begin{array}{l}4200- \\
23850\end{array}$ & $\begin{array}{c}100- \\
370\end{array}$ \\
\hline HE2 & Plate-fin & $\begin{array}{c}\Delta \mathrm{p}=0.015 \\
\mathrm{~T}_{\text {LNG.in }}=-128^{\circ} \mathrm{C} \\
\mathrm{T}_{\text {GNG.out }}=60^{\circ} \mathrm{C}\end{array}$ & $\begin{array}{l}1575- \\
4650\end{array}$ & $10-50$ \\
\hline
\end{tabular}

Table 4 reports the summary of component parameters (cost and weight). Besides, it contains the main assumption on the components parameters based on their type and scale (efficiency of turbomachinery, effectiveness and relative pressure losses of HE1). The effectiveness of HE1 associated with HE type has been assigned as reasonably achievable for the particular type. The effectiveness of HE2 is not fixed being determined in HE2 by the flow rates and temperatures of the mediums. For any of the cases, it does not exceed 0.82 for the cold side and 0.19 for the hot side. Temperature before the compressor takes the value between 60 and $85^{\circ} \mathrm{C}$. It was checked that condensation does not occur under these pressure and temperature, as with the lower temperature, it is possible [16]. 
Results of the system performance in different configurations, HE1 hot side effectiveness, and phase of the truck operation are shown in Table 5. Calculated engine power in the Motorway phase (phase-3) equals to $102 \mathrm{~kW}$, and in Rural phase (phase-2), it is equal to $88.5 \mathrm{~kW}$. As mentioned before, the WHR system is bypassed in the Urban phase. The maximum useful power produced by IBC $\left(\mathrm{P}_{\mathrm{IBC}}\right)$ is reached in the Motorway phase with HE1 of the higher effectiveness (average IBC power $\left(\mathrm{P}_{\mathrm{IBC}}\right) 2.75 \mathrm{~kW}, 2.70 \%$ of the fuel economy (FE). Maximal total FE for this configuration for the whole ETC is $2.14 \%$. The range of $\mathrm{FE}_{\text {tot }}$ is associated with the varying WHR system weight. Generated power partially covers electric consumption of the vehicle auxiliaries, which is in the range $4.7-7.3 \%$ according to [28].

The optimal pressure ratio is in the range from 1.8 to 2.5 and fits the values reachable by the ordinary onestage radial turbomachines. Figure 3 shows the sensitivity analysis providing the choice of the optimal pressure after the turbine for each case and the optimal value of the corresponding pressure ratio (PR).

Table 5. Results of two configurations with different effectiveness of HE1 for two engine conditions

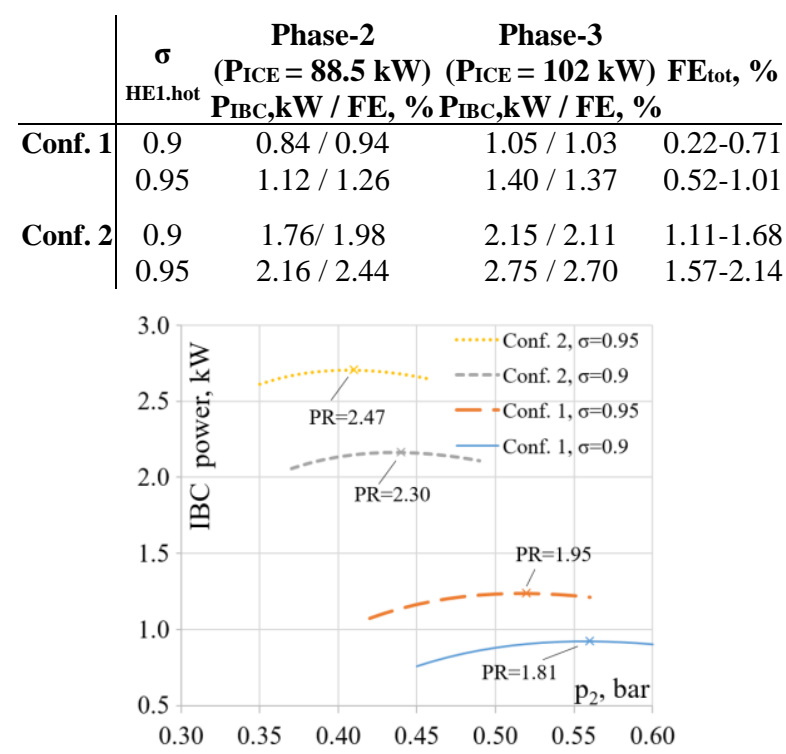

Fig. 3. Sensitivity analysis of IBC power versus the lowest pressure of IBC

Figure 4 shows the performance of the studied system in the first configuration, without the LNG phase change involved. For the whole range of WHR system weight and lower or higher effectiveness of HE1, the system cannot compensate even the lowest investment cost at the 1400 thousand $\mathrm{km}$ of the truck run. This value corresponds approximately to a truck lifetime of 10 years. The second configuration, Figure 5, leads to better results, crossing the lowest investment cost line at about 1000 thousand $\mathrm{km}$ of the truck run with the system of the highest HE effectiveness and lowest weight. Considering the fact that the cash flow discounting and O\&M cost were neglected in this work, such a result could not be considered promising from the point of view of economically driven investments in the current situation with fuel prices and $\mathrm{CO}_{2}$ regulation.

As a possibility for future analysis, other configurations might be studied, where the existing engine system is upgraded with additional radiators. However, the outlook is challenging because, together with the growing efficiency, these changes in the system configuration might bring a significant increment of the cost and aerodynamical resistance of the truck. Only the mass production effect, lower HEs prices, and stricter $\mathrm{CO}_{2}$ regulation might bring the technology to the acceptable payback time.

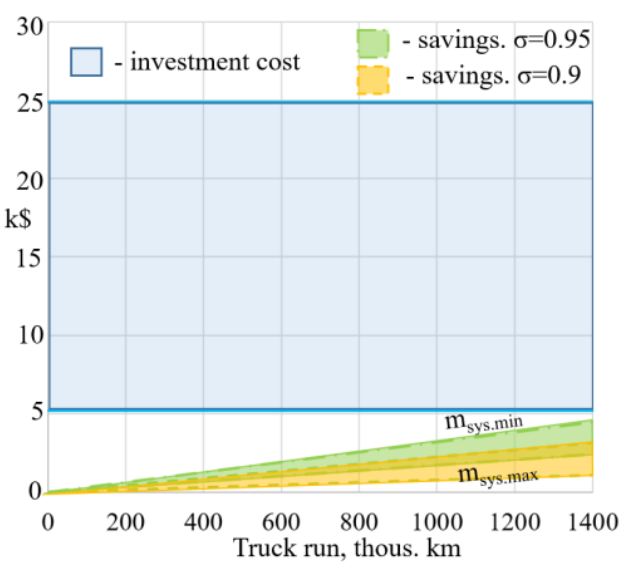

Fig. 4. Investments and savings. Configuration 1 (only HE1)

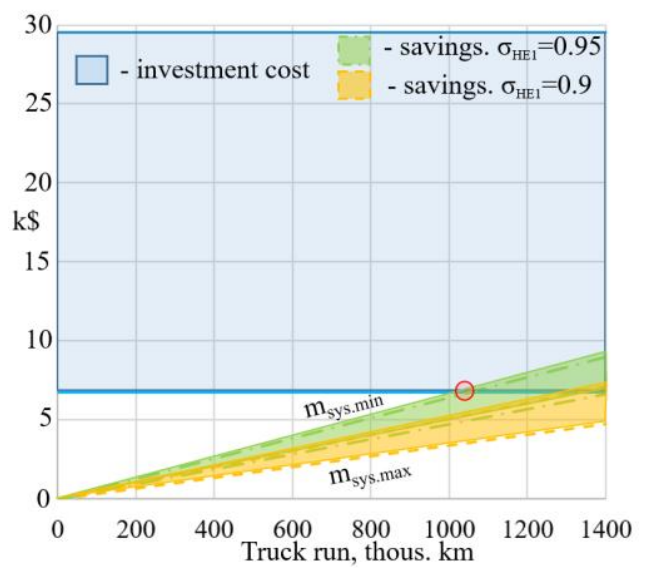

Fig. 5. Investments and savings. Configuration 2 (HE1 and HE2)

\section{Conclusion}

An integrated waste heat recovery (WHR) system based on the inverted Brayton cycle (IBC) applied to a liquefied natural gas (LNG) fuelled truck was studied in this paper. Experimental data from literature were used for a primary assessment of the truck performance under three standard truck driving phases: Motorway, Rural, and Urban. An evaluation of the investment cost of the equipment was conducted with different approaches. Two suitable types of heat exchangers (HEs), namely shell-and-tube and plate-fin, with corresponding achievable effectiveness and reasonable pressure losses and weight were considered for the system. The study focused on two configurations of the system: one of 
them use only the engine coolant for cooling of the exhaust gas, and the second one also uses the LNG phase change.

The first configuration cost is assessed in a range 5180-24855 \$, the second configuration: 6755-29515 \$. Both of them have shown the best performance in the Motorway phase of operation $(1.4 \mathrm{~kW}$ and $2.75 \mathrm{~kW}$ correspondingly) when equipped with heat exchangers of higher effectiveness. The total fuel economy for the whole driving cycle is $2.08 \%$ in the best case. Finally, the cash flow associated with the saved fuel cost was compared with the investment cost of the system. The result has shown that in the best case (configuration 2 with the high-effectiveness HE), the studied WHR system can compensate the investment cost only after 1 000 thousand $\mathrm{km}$ of the truck run. In all other scenarios, the system reaches payback moment after 1400 thousand $\mathrm{km}$, or more than ten years of exploitation, coming close to the system and truck lifetime.

With the current economic situation in the energy sector and existing technologies of HE production, the studied WHR unit is not economically beneficial as the retrofit system. However, regulations continuous development in the energy sector, as well as mass production, might significantly improve the economic assessment. The configurations suitable for the embedded integration are to be studied in future.

\section{Nomenclature}

$\sigma$ HE effectiveness, -

A heat-transfer area, $\mathrm{m}^{2}$

FE fuel economy, $\%$

$\mathrm{m}$ mass, $\mathrm{kg}$

$\mathrm{p}$ pressure, bar

$\Delta \mathrm{p}$ relative pressure losses, -

$\mathrm{P}$ power, $\mathrm{kW}$

$\mathrm{T}$ temperature, ${ }^{\circ} \mathrm{C}$

$\mathrm{U}$ effective overall heat conductance, $\mathrm{W} / \mathrm{m}^{2} \mathrm{~K}$

$\mathrm{V}$ volume, $\mathrm{m}^{3}$

Abbreviations

HE heat exchanger

IBC inverted Brayton cycle

O\&M operation and maintenance

ORC organic Rankine cycle

PR pressure ratio

WHR waste heat recovery

\begin{tabular}{llll}
\multicolumn{3}{c}{ Subscripts } \\
act & active & is & isentropic \\
C & refer to compressor & oil & engine oil \\
cold & refer to cold side of HEORC & refer to ORC \\
eff & effective & out & outlet \\
1 & per litre & T & refer to turbine \\
IBC & refer to IBC & tot & total \\
hot & refer to hot side of HE & sys & system \\
in & inlet & veh & vehicle
\end{tabular}

\section{References}

[1] Regulation (EU) 2019/1242 of the european parliament and of the council 1 198/202. European Union: https://eur-lex.europa.eu/; 2019.

[2] Iveco Stralis LNG natural power report on testing of Iveco LNG vehicles in Poland. 2016. www.cryogas.pl/pliki_do_pobrania/artykuly/Cr yogas_IVECO_Report._Polish_road_tests_pdf

[3] Bianchi M, De Pascale $\bar{A}$. Bottoming cycles for electric energy generation: Parametric investigation of available and innovative solutions for the exploitation of low and medium temperature heat sources. Appl Energy 2011;88:1500-9.

[4] Schaijk J. Iveco Euro VI LNG PEMS test report. Helmond: 2018.

[5] Swedish In-Service Testing Program On Emissions from Heavy-Duty Vehicles. 2016. https://transportstyrelsen.se/globalassets/global /vag/miljo/tunga-fordon--2016.pdf.

[6] Hill N, Norris J, Kirsch F, Dun C, McGregor $\mathrm{N}$, Pastori E, et al. Light weighting as a means of improving Heavy Duty Vehicles' energy efficiency and overall CO2 emissions. 2015.

[7] Rural / Urban / Motorway. COMMISSION REGULATION (EU) No 582/2011. 2011.

[8] Zhang Q, Xu Z, Li M, Shao S. Combustion and emissions of a Euro VI heavy-duty natural gas engine using EGR and TWC. J Nat Gas Sci Eng 2016;28:660-71.

[9] Natural gas for vehicles | Liquefied natural gas http://cngeurope.com/

[10] Exchange Rates - Historical Chart n.d. https://www.macrotrends.net/charts/exchangerates (accessed July 4, 2020).

[11] Dunteman NRA. A new look at the competitive position of the inverted-cycle gas turbine for waste-heat utilization and other applications. Massachusetts Institute of Technology, 1970.

[12] Kennedy I, Ceen B, Jones S, Chen Z, Copeland CD. Inverted Brayton Cycle With Exhaust Gas Condensation. J Eng Gas Turbines Power 2018.

[13] Di Battista D, Carapellucci R, Cipollone R. Integrated evaluation of Inverted Brayton cycle recovery unit bottomed to a turbocharged diesel engine. Appl Therm Eng 2020;175:115353.

[14] Di Battista D, Fatigati F, Carapellucci R, Cipollone R. Inverted Brayton Cycle for waste heat recovery in reciprocating internal combustion engines. Appl Energy 2019;253:113565.

[15] Ferrari G. Motori a Combustione Interna. Bologna: Società Editrice Esculapio; 2019.

[16] Abrosimov KA, Baccioli A, Bischi A. Technoeconomic analysis of combined inverted Brayton - Organic Rankine cycle for hightemperature waste heat recovery. Energy Convers Manag 2020;207:15.

[17] Amazon.com: Turbo charger fit Volvo D12 2020.

https://www.amazon.com/dp/B083QTTT4P/ref =cm_sw_em_r_mt_dp_U_rMXbFbRJ6MV84

[18] Turton R, Bailie RC, Whiting WB, Shaeiwitz JA. Analysis, Synthesis and Design of Chemical Processes. 3rd ed. Pearson Education; 2008.

[19] Humphreys KK, editor. Project and Cost Engineers' Handbook. New York: CRC Press; 2004. 
[20] Hewitt GF, Pugh SJ. Approximate design and costing methods for heat exchangers. Heat Transf Eng 2007;28:76-86.

[21] Kananeh AB, Peschel J. Fouling in Plate Heat Exchangers: Some Practical Experience. In: Dr. Jovan Mitrovic, editor., InTech; 2012, p. $533-50$.

[22] Sinnott RK, Coulson JM, Richardson JF. Coulson and Richardson's chemical engineering. Vol. 6, Chemical engineering design. 4th ed. Elsevier ButterworthHeinemann; 2005.

[23] ESDU, Selection and Costing of Heat Exchangers, Plate-Fin Type, item No. 97006. ESDUdata 1997.

[24] Chemical Engineering - Chemical Engineering essentials for the global chemical processing industries (CPI) 2019. https://www.chemengonline.com/

[25] Xie GN, Sunden B, Wang QW. Optimization of compact heat exchangers by a genetic algorithm. Appl Therm Eng 2008;28:895-906.

[26] Alibaba.com n.d. https://www.alibaba.com/

[27] Dorosz P, Wojcieszak P, Malecha Z. Exergetic Analysis, Optimization and Comparison of LNG Cold Exergy Recovery Systems for Transportation. Entropy 2018;20:59.

[28] Pettersson N, Johansson KH. Modelling and control of auxiliary loads in heavy vehicles. Int J Control 2006;79:479-95. 